\title{
Standardizing definitions for hybrid coronary revascularization
}

\author{
Ralf E. Harskamp, MD, ${ }^{\mathrm{a}, \mathrm{e}}$ Johannes O. Bonatti, MD, ${ }_{\mathrm{b}}$ David X. Zhao, MD, PhD, ${ }^{\mathrm{c}}$ John D. Puskas, MD, ${ }^{\mathrm{d}}$ \\ Robbert J. de Winter, MD, PhD, ${ }^{\mathrm{e}}$ John H. Alexander, MD, MHS, ${ }^{\mathrm{a}}$ and Michael E. Halkos, $\mathrm{MD}^{\mathrm{d}}$
}

The optimal revascularization strategy for patients with multivessel coronary artery disease remains controversial. Coronary artery bypass grafting $(\mathrm{CABG})$ surgery is still considered the criterion standard, but percutaneous coronary intervention (PCI) has become the preferred strategy for most patients with coronary artery disease. ${ }^{1,2}$ Numerous studies have compared outcomes after CABG and multivessel PCI. In general, it is accepted that CABG surgery has the advantage of superior long-term freedom from repeat revascularization, as well as a survival benefit in certain high-risk groups, but that these benefits come at the expense of a higher risk of periprocedural stroke and other in-hospital complications, as well as a longer recovery time. ${ }^{3-5}$ An alternative approach that would combine both CABG and PCI was first developed in the late 1990s. ${ }^{6}$ This integrated approach was subsequently referred to as "integrated coronary revascularization" or "hybrid coronary revascularization" (HCR), in which the term hybrid reflected the mixture of therapies drawn from different subspecialties (CABG and PCI) that were used to achieve coronary revascularization. The current evidence for the use of HCR is limited to nonrandomized, singleinstitution or multicenter experiences that have used various clinical criteria and definitions, as well as techniques. ${ }^{7,8}$ For comparative effectiveness studies, as well as for the use in clinical practice, a more uniform definition of HCR is of utmost importance. In this article, we will discuss the currently used definitions and the issues that arise when implementing these definitions, and we will propose a more uniform definition of HCR derived from existing definitions.

\section{CURRENTLY USED DEFINITIONS}

A number of societies, including the Society of Thoracic Surgeons (STS), National Cardiovascular Data Registry

From the Duke Clinical Research Institute, ${ }^{\text {a }}$ Duke Medicine, Durham NC; the Department of Thoracic and Cardiovascular Surgery, ${ }^{b}$ Cleveland Clinic, Cleveland Ohio, and Cleveland Clinic, Abu Dhabi, United Arab Emirates; the Heart and Vascular Center of Excellence at Wake Forest Baptist Medical Center, Winston-Salem, NC; the Division of Cardiothoracic Surgery, ${ }^{\mathrm{d}}$ Emory University School of Medicine, Atlanta Ga; and the Department of Cardiology of the Academic Medical Center, ${ }^{\mathrm{e}}$ University of Amsterdam, Amsterdam, The Netherlands. Disclosures: John H. Alexander reports research grants from Bristol Myers Squibb, CLS Behring, National Institutes of Health, and Regado Biosciences and consulting fees for Moerae Matrix and VA Cooperative Studies program. Michael E. Halkos reports consulting fees from Intuitive. All other authors have nothing to disclose with regard to commercial support.

Received for publication Oct 13, 2013; accepted for publication Oct 23, 2013; available ahead of print Nov 25, 2013

Address for reprints: Ralf E. Harskamp, MD, 2400 Pratt St, Office 7047B, Durham, NC 27705 (E-mail: r.e.harskamp@gmail.com).

J Thorac Cardiovasc Surg 2014;147:556-60

$0022-5223 / \$ 36.00$

Copyright (c) 2014 by The American Association for Thoracic Surgery

http://dx.doi.org/10.1016/j.jtcvs.2013.10.019
CathPCI Registry, American College of Cardiology, and European Society of Cardiology, have introduced definitions for hybrid procedures in the setting of coronary revascularization. ${ }^{9-13}$ Table 1 summarizes the various definitions that are currently applied by these national databases and national and international societies. The widest definition is used by the STS, in which hybrid procedures include all planned and unplanned combinations of procedures that combine a surgical and transcatheter interventional approach during a single hospital stay. ${ }^{9}$ The guidelines of the joint American societies on $\mathrm{PCI}^{11}$ and $\mathrm{CABG}^{12}$ use a much stricter definition for HCR, in which procedures have to be planned and should involve a combination of left internal thoracic artery (LITA) to left anterior descending artery (LAD) grafting and PCI of at least one non-LAD coronary artery. As can also be seen in Table 1, the definition of HCR in comparison studies registered at clinicaltrials.gov also follow these stricter joint American society guideline definitions, suggesting that this definition reflects the most optimal strategy for performing HCR. The question is whether these restricted definitions should be used or whether definitions should be expanded to include other, less favorable, combinations of percutaneous and surgical revascularization techniques.

\section{THE ISSUE OF "UNPLANNED" HCR PROCEDURES}

There is debate regarding whether to include patients whose procedures are considered "unplanned" when surgical and percutaneous coronary revascularization are performed in 2 stages. In the STS database, for instance, cases were considered unplanned HCR when either PCI or CABG was performed after incomplete revascularization or graft closure during the same hospital admission. ${ }^{9}$ The inclusion of graft closure is particularly troublesome, and in our view unplanned HCR for these cases is a misnomer for a $C A B G$ procedure that was complicated by acute graft failure that required a repeat intervention. The converse misclassification may also occur, when $\mathrm{CABG}$ is performed because of complications arising from PCI. In our opinion, these cases should not be considered HCR procedures; rather, they should be classified as complications of the index procedure. Complementarily, patients undergoing CABG who subsequently undergo PCI because of incompletely revascularized territories that were not grafted should be considered as undergoing unplanned HCR. 
TABLE 1. Currently used definitions for hybrid coronary revascularization

Guideline/registry

2011 ACCF/AHA/SCAI Guidelines for PCI; 2011 ACCF/AHA Guidelines for $\mathrm{CABG}^{11,12}$

2010 ESC/EACTS Guidelines on Myocardial Revascularization ${ }^{10}$

STS Adult Cardiac Registry National Database (version 2.73)

NCDR CathPCI Registry (version 4.4) ${ }^{13}$

Clinicaltrials.gov (definitions by registered studies)

Definition

The planned combination of LITA-LAD artery grafting and PCI of $\geq 1$ non-LAD coronary arteries. Hybrid coronary revascularization may be performed in a hybrid suite in a single operative setting or as a staged procedure (PCI and CABG performed in 2 different operative suites, separated by hours to $2 \mathrm{~d}$, but typically during the same hospital stay).

Planned, intentional combination of $\mathrm{CABG}$, with a catheter-based intervention to other coronary arteries during the same hospital stay. Procedures can be performed consecutively in a hybrid operating room or sequentially on separate occasions in the conventional surgical and PCI environments.

A hybrid procedure is defined as a procedure that combines surgical and transcatheter interventional approaches: (1) planned, concurrent is performed in same setting; (2) planned, staged is performed in the same hospital admission; (3) unplanned is performed after incomplete revascularization or graft closure during the same hospital admission.

Hybrid therapy occurs when both surgical and percutaneous coronary revascularization are planned, with different lesions treated with the different techniques.

Minimal invasive LITA-to-LAD and PCI of non-LAD lesions. Procedures can be performed either in the same operating suite or during the same hospitalization

$A C C F$, American College of Cardiology Foundation; $A H A$, American Heart Association; SCAI, Society for Cardiovascular Angiography and Interventions; PCI, percutaneous coronary intervention; $C A B G$, coronary artery bypass grafting; LITA, left internal thoracic artery; LAD, left anterior descending artery; ESC, European Society of Cardiology; EACTS, European Association for Cardio-Thoracic Surgery; STS, Society of Thoracic Surgeons; NCDR, National Cardiovascular Data Registry.

\section{HCR PROCEDURES IN THE SETTING OF ACUTE ST-SEGMENT ELEVATION MYOCARDIAL INFARCTION}

It is controversial whether patients with acute ST-segment elevation myocardial infarction who underwent PCI (with or without stenting) for the infarct related artery and subsequent emergency CABG through a sternotomy of the non-infarct related coronary arteries should be considered as having undergone HCR. This warrants special consideration for patients in whom the LAD was initially treated percutaneously with balloon angioplasty only. In these patients, angioplasty is typically used to interrupt the infarct, and the LAD is typically then bypassed during $\mathrm{CABG}$ surgery. The latest European guidelines on myocardial revascularization consider acute ST-segment elevation myocardial infarction cases in which primary PCI is performed for a non-LAD culprit vessel followed by $\mathrm{CABG}$ for complete revascularization as procedures performed with a "hybrid approach." 10 The CathPCI Registry and the STS registry consider these cases planned hybrid procedures, as long as both procedures are performed during the same hospital admission. ${ }^{13}$ In our opinion, patients undergoing emergency PCI of the infarct-related artery followed by $\mathrm{CABG}$ of both the infarct-related artery and non-infarct related territories should not be considered HCR. Patients who undergo emergency or urgent PCI of an infarct-related artery followed by bypass grafting of non-infarct-related territories, however, should technically be considered as undergoing HCR procedures as long as the decision to follow this approach was made before PCI was undertaken.

\section{WHAT IF A BYPASS GRAFT OTHER THAN THE LITA IS USED FOR HCR?}

The rationale for performing $\mathrm{HCR}$ in most cases is to provide revascularization to the LAD with the LITA, because of its superior patency. ${ }^{14}$ In some cases, however, multiple left-sided arterial grafts are performed with either internal thoracic artery used to graft the LAD and 1 or more other left-sided targets. In these cases, PCI is used to treat the right coronary or the remaining left non-LAD coronary arteries. Similarly, saphenous vein grafts may also be used to graft LAD or non-LAD leftsided vessels, followed by PCI of remaining vessels. For purposes of definition, these cases should be considered hybrid cases. Currently, an increasing number of cases are being reported in which minimally invasive double internal thoracic artery grafting is combined with PCI for treatment of complex multivessel disease. ${ }^{15}$ A subclassification, such as "advanced HCR", or "complex HCR," has been proposed for these procedures, to differentiate these cases from HCR that uses single-vessel CABG.

\section{WHAT IF THE SURGICAL PROCEDURE IS PERFORMED THROUGH A CONVENTIONAL STERNOTOMY?}

Although most centers that perform HCR use minimally invasive techniques, one should also consider the use of 
median sternotomy with LITA-LAD grafting as HCR, as long as PCI is performed for at least 1 non-LAD lesion. A subclassification is justified, however, because minimally invasive techniques require a different skill set and overall have a different risk profile and fewer complications than do full sternotomy procedures. For example, sternal wound complications would be nonexistent with sternal-sparing approaches. One of the benefits of less-invasive surgical revascularization is the potentially shorter recovery period and faster return to normal activities associated with sternal-sparing approaches. Several authors have shown better quality of life scores and functional recovery with minimally invasive HCR relative to transsternal CABG. ${ }^{16-18}$ Therefore, although we believe that HCR procedures should include those that use a full median sternotomy approach, additional subclassification is necessary to distinguish them from minimally invasive procedures that use a partial sternotomy, lateral thoracotomy, or thoracoscopic approach. Most of these subclassifications already exist in the latest version of the STS database but are lacking in the CathPCI Registry.

\section{THE SEQUENCE AND TIME INTERVAL OF SURGICAL AND PERCUTANEOUS PROCEDURES}

HCR consists of 2 separate procedures that can be performed in a hybrid operating room within minutes of each other (referred to as "simultaneous," "one-stage," "one-stop," or "concurrent") or within hours, days, or even weeks of each other by using the conventional operating theater and catheterization laboratories to perform the procedures (referred to as "2-staged" or "staged"). ${ }^{19}$ Surgical revascularization is usually performed first, followed by PCI, and when a 2-staged plan is used, most centers perform the procedures within the same hospital stay. Two-staged HCR procedures with LITA-LAD grafting and PCI performed during separate hospital admissions, either at the same or different institutions, are also common occurrences. This could be a particularly useful approach in patients with complex disease, as well as in patients with specific comorbidities, such as renal failure, for whom 2-staged HCR could potentially lower the risk of periprocedural complications associated with surgery and PCI. HCR procedures performed at different institutions may increase adoption of HCR as a mainstream revascularization option, because interventional cardiologists can perform the PCI in their own referring centers. From a research perspective, these cases pose a number of challenges related to data capturing. Current national registries, such as the CathPCI Registry and the STS database, define HCR as a combination of CABG and PCI procedures that occur during the same hospital stay. When HCR is performed in 2 different hospitals or during 2 hospitalizations, some staged HCR cases may currently be misclassified because the second part of HCR is considered a repeat revascularization procedure, even though the intention to treat was HCR. Therefore we believe that these combinations of procedures should be considered HCR irrespective of the sequence and timing if the intent to treat is HCR procedure, as long as both procedures occur within 60 days of each other and the second stage of the procedure is elective. Patients who are seen urgently before to their second stage because of interim ischemia should be classified as undergoing a repeat intervention. Although this definition could be used in clinical trials as well as registries with longitudinal follow-up, or those that document the intent to perform HCR in addition to whether HCR is actually performed, the usefulness of this definition in the STS database and CathPCI Registry is limited, because patients in these registries are only followed up during index hospitalization or to 30 days. Thus patients for whom the second stage of the HCR procedure is performed after index hospitalization or after 30 days are unlikely to be captured. This same limitation applies to patients who undergo PCI first during a separate hospitalization. Whether these patients are being captured as undergoing HCR in either the CathPCI Registry or STS database is unclear and depends on accurate documentation and coding, and this is an important limitation of current database comparisons for 2-staged HCR procedures with other revascularization strategies.

\section{KEY ELEMENTS FOR HCR}

The principle element that determines HCR is that a combination of surgical and percutaneous techniques is chosen with the a priori intent of providing complete coronary revascularization, with the 2 procedures scheduled and performed within a predefined period (Figure 1). This means that HCR should always be defined on an intent-to-treat basis, which requires that the use of a hybrid approach be discussed before the performance of either surgical or percutaneous coronary revascularization.

In summary, we propose the following classification system for HCR for patients with multivessel coronary artery disease:

1. Planned use of CABG and PCI techniques for revascularization of different coronary territories

2. Both stages of HCR procedures being performed within 60 days of each other, either during the same or different hospital encounters, regardless of each procedure's location

3. Neither the CABG nor PCI portion of the procedure being performed for complications of either procedure

4. Inclusion of both 1-stage and 2-stage approaches, with either LITA-LAD grafting or PCI performed first

5. Inclusion of any of scenarios 1 through 4 regardless of surgical approach (choice of incision) 


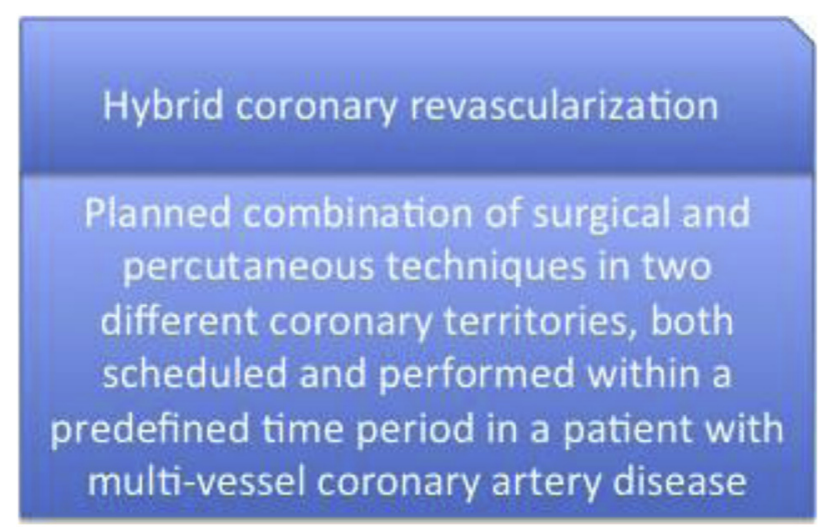

\section{Sub-classification}

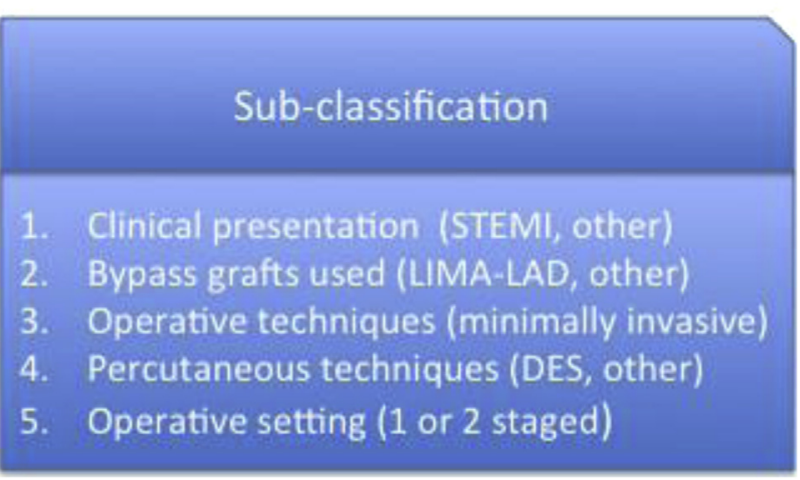

FIGURE 1. Proposed definition for hybrid coronary revascularization. STEMI, ST-segment elevation myocardial infarction; LITA-LAD, left internal thoracic artery to left anterior descending artery grafting; $D E S$, drug-eluting stent.

6. Exclusion of cases in which patients present with acute ST-segment elevation myocardial infarction and undergo balloon angioplasty or stenting of the infarctrelated artery followed by multivessel CABG that also involves revascularization of the infarct-related territory

Subclassification of the HCR procedure should then be based on clinical presentation, type and number of bypass grafts used, use of minimally invasive techniques, and the sequence and time interval of surgical and percutaneous approaches.

\section{CONCLUSIONS}

HCR encompasses the use of a variety of surgical and percutaneous techniques to accomplish complete coronary revascularization and ultimately improve patient outcomes. The variability in implementation of new surgical and percutaneous technologies, as well as clinical indications among centers that perform HCR, creates considerable heterogeneity. In this article, we have proposed a standardized definition as well as a subclassification for HCR procedures that may be helpful not only in clinical practice but also for clinical research. Future efforts should focus on further refining and harmonizing definitions that are currently used by national registries.

\section{References}

1. Epstein AJ, Polsky D, Yang F, Yang L, Groeneveld PW. Coronary revascularization trends in the United States: 2001-2008. JAMA. 2011;305: 1769-76.

2. Riley RF, Don CW, Powel W, Maynard C, Dean LS. Trends in coronary revascularization in the United States from 2001 to 2009: recent declines in percutaneous coronary interventions volumes. Circ Cardiovasc Qual Outcomes 2011;4:193-7.

3. Serruys PW, Morice M, Kappetein AP, Colombo A, Holmes DR, Mack MJ, et al. Percutaneous coronary intervention versus coronary-artery bypass grafting for severe coronary artery disease. $N$ Engl J Med. 2009;360:961-72.

4. Farkouh ME, Domanski M, Sleeper LA, Siami FS, Dangas G, Mack M, et al. Strategies for multivessel revascularization in patients with diabetes. $N$ Engl J Med. 2012:367:2375-84.

5. Palmerini T, Biondi-Zoccai G, Riva DD, Mariani A, Savini C, Di Eusanio M, et al. Risk of stroke with percutaneous coronary intervention compared with on-pump and off-pump coronary artery bypass graft surgery: evidence from a comprehensive network meta-analysis. Am Heart J. 2013;165:910-7.

6. Angelini GD, Wilde P, Salerno TA, Bosco G, Calfiore AM. Integrated left small thoracotomy and angioplasty for multivessel coronary artery revascularisation. Lancet. 1996;347:757-8.

7. Shen L, Hu S, Wang H, Xiong H, Zheng Z, Li L, et al. One-stop hybrid coronary revascularization versus coronary artery bypass graft and percutaneous coronary intervention for the treatment of multivessel coronary artery disease: 3-year follow-up results from a single institution. J Am Coll Cardiol. 2013;61: 2525-33.

8. Halkos ME, Rab ST, Vassiliades TA, Morris DC, Douglas JS, Kilgo PD, et al. Hybrid coronary revascularization versus off-pump coronary artery bypass for the treatment of left main coronary stenosis. Ann Thorac Surg. 2011;92:2155-60.

9. STS [Internet]. Chicago: The Society; c2013 [cited 2013 Jul 20]. STS National Database/Data Managers/Adult Cardiac Surgery Database/Data Collection version 2.73. Available from: http://www.sts.org/sts-nationaldatabase/database-managers/adult-cardiac-surgery-database/data-collection/.

10. Task Force on Myocardial Revascularization of the European Society of Cardiology (ESC) and the European Association for Cardio-Thoracic Surgery (EACTS); European Association for Percutaneous Cardiovascular Interventions (EAPCI)Wijns W, Kolh P, Danchin N, Di Mario C, Falk V, Folliguet T, et al. Guidelines on myocardial revascularization. Eur Heart J. 2010;31:2501-55.

11. Levine GN, Bates ER, Blankenship JC, Bailey SR, Bittl JA, Cercek B, et al. 2011 ACCF/AHA/SCAI Guideline for Percutaneous Coronary Intervention: a repor of the American College of Cardiology Foundation/American Heart Association Task Force on Practice Guidelines and the Society for Cardiovascular Angiography and Interventions. Circulation. 2011;124:e574-651.

12. Hillis LD, Smith PK, Anderson JF, Bittl JA, Bridges CR, Byrne JG, et al 2011 ACCF/AHA Guideline for Coronary Artery Bypass Graft Surgery: executive summary: a report of the American College of Cardiology Foundation/American Heart Association Task Force on Practice Guidelines Circulation. 2011;124:2610-42. Erratum in: Circulation. 2011;124:e956. Circulation. 2012;126:e105.

13. The National Cardiovascular Data Registry [Internet]. Washington, DC American College of Cardiology Foundation; c2013 [2013 Jul 20]. NCDR CathPCI Registry version 4.4 coder's data dictionary. Available from: https:// www.ncdr.com/WebNCDR/docs/public-data-collection-documents/cathpci_v4_ codersdictionary_4-4.pdf.

14. Goldman S, Zadina K, Moritz T, Ovitt T, Sethi G, Copeland JG, et al. Long-term patency of saphenous vein and left internal mammary artery grafts after coronary artery bypass surgery: results from a Department of Veterans Affairs Cooperative Study. J Am Coll Cardiol. 2004;44:2149-56.

15. Leed JD, Vesely MR, Zimrin D, Bonatti JO. Advanced hybrid coronary revascularization with robotic totally endoscopic triple bypass surgery and left main percutaneous intervention. J Thorac Cardiovasc Surg. 2012;144: 986-7.

16. Bachinsky WB, Abdelsalam M, Boga G, Kiljanek L, Mumtaz M, McCarty C Comparative study of same sitting hybrid coronary artery revascularization versus off-pump coronary artery bypass in multivessel coronary artery disease. J Interv Cardiol. 2012;25:460-8. 
17. Kon ZN, Brown EN, Tran R, Joshi A, Reicher B, Grant MC, et al. Simultaneous hybrid coronary revascularization reduces postoperative morbidity compared with results from conventional off-pump coronary artery bypass. J Thorac Cardiovasc Surg. 2008;135:367-75.

18. De Cannière D, Jansens JL, Goldschmidt-Clermont $\mathrm{P}$, Barvais L, Decroly P, Stoupel E. Combination of minimally invasive coronary bypass and percutaneous transluminal coronary angioplasty in the treatment of double-vessel coronary disease: Two-year follow-up of a new hybrid proce dure compared with "on-pump" double bypass grafting. Am Heart J. 2011; 142:563-70.

19. Harskamp RE, Zheng Z, Alexander JH, Williams JB, Xian Y, Halkos ME, et al. Status quo of hybrid coronary revascularization for multi-vessel coronary artery disease. Ann Thorac Surg. October 28, 2013 [Epub ahead of print]. 